\title{
Sobre Como as florestas pensam
}

KoHn, Eduardo. How Forests Think. Berkeley, University of California Press, 2013, 288 pp.

Marcos de Almeida Matos

Universidade Federal do Acre

Universidade Federal de Santa Catarina

O livro How Forests Think de Eduardo Kohn representa uma contribuição importante ao que se convencionou chamar de "virada ontológica" na antropologia. Segundo o autor, seu principal objetivo é mobilizar a etnografia realizada entre os Runa (Equador) para "pensar ontologicamente". Entretanto, Kohn atribui um sentido específico a este movimento: a antropologia deve formular teses sobre a "natureza da realidade" (p. 9), ou "teses gerais sobre o mundo" (p. 94), transformando-se em algo mais que uma teoria sobre o entendimento alheio. Assim, se o nome do livro ecoa alguns títulos clássicos da antropologia - como La Mentalité Primitive de Lucien Lévy-Bruhl, How "Natives" Think de Marshall Sahlins, How We Think They Think de Maurice Bloch, ou ainda La Pensée Sauvage de Claude Lévi-Strauss -, a "virada ontológica" deve, segundo Kohn, reconfigurar a pergunta do antropólogo: a questão colocada pelo livro é sobre como as florestas pensam, e não sobre como os nativos pensam que a floresta pensa (p. 94).

O primeiro capítulo, "The Open Whole", apoia-se na leitura de Peirce feita por Terence Deacon, e procura descrever a interação entre os processos semióticos que ocorrem nas florestas. Kohn evoca a tripartição peirceana entre o ícone, o índice e o símbolo, alinhando os 
REVISTA DE ANTROPOlOGIA, SÃo PAULO, USP, $20 \mathrm{I} 5$, V. $58 \mathrm{~N}^{\circ} \mathrm{I}$.

três tipos de signo em um padrão de encaixamento hierárquico: símbolos supóem índices, e índices supóem ícones, sendo que cada nível possui propriedades emergentes únicas, irredutíveis às características dos níveis de base (pp. 50-51). Ao contextualizar a semiose simbólica (reputada como distintivamente humana repetidas vezes ao longo do livro) entre outros tipos de processamento semiótico, o autor busca mostrar como, apesar das definiçóes tradicionais da cultura e da sociedade como totalidades coerentes, os homens vivem em universos abertos e permeados por modos semióticos não-humanos. Isto levaria à ultrapassagem das dicotomias constituintes de uma vulgata epistemológica ocidental, que opôe sujeito e objeto, ou que opóe uma realidade sociocultural e histórica a uma realidade objetiva ou natural, composta de coisas e processos biológicos.

Compreender o mundo para além destes dualismos típicos envolve "provincializar" a linguagem (sensu Dipesh Chakrabarty), ou "descolonizar o pensamento" (sensu Viveiros de Castro): trata-se de elaborar um conceito de pensamento que não esteja restrito à linguagem, ao simbólico ou ao humano (p. 41). Para Kohn, a maneira mais produtiva de superar a compreensão dualista seria pensar a representaçáo como uma propriedade do mundo, e náo apenas da mente humana. Não se trata assim de abandonar a ideia de representação (p. 41), mas antes de "desfamiliarizar" o signo arbitrário, próprio às semióticas simbólicas, abrindo espaço para a compreensão de outros tipos de signo. Os signos, ele insiste, não são objetos exclusivamente humanos: "all living beings sign" (p. 42). Ou, dito de outro modo, "lives and thoughts are not distinct kinds of things. [...] Selves are signs. Lives are thoughts. Semiosis is alive" (p. 99). Neste contexto, as florestas são compreendidas como redes de processos semióticos (p. 42), "an emergent and expanding multilayered cacophonous web of mutually constitutive, living, and growing thoughts" (p. 79). 
REVISTA DE ANTROPOLOGIA, SÃO PAULO, USP, $20 \mathrm{I}$, V. 58 N $\mathrm{N}^{\mathrm{O}} \mathrm{I}$.

Em "The Living Thought", o segundo capítulo do livro, Kohn procura mostrar por que se pode dizer que tudo o que é vivo pensa, inclusive as florestas. O capítulo aborda a lógica associativa dos "pensamentos vivos", bem como o tema tyloriano do animismo: se existem pensamentos para além do humano, então os humanos não são os únicos egos (selves) no mundo, existiriam outros tipos de "nós" (p. 72). O animismo é descrito por Kohn como uma "prática incorporada" (p. 73), que permite aos Runa participarem com sucesso na rede de relaçóes vivas na floresta. Ele alega que deveríamos, a partir do animismo, repensar a relacionalidade, "provincializando a linguagem", isto é, recusando a aplicação dos modelos de relacionalidade linguística sobre as formas de relação entre os egos (selves) - um dos limites que ele reputa como jamais superados pela antropologia simbólica (p. 73).

$\mathrm{O}$ autor argumenta ainda que a antropologia deveria ampliar o seu escopo, até a elaboração de uma concepção geral da vida como conjunto de processamentos semióticos (p. 74). Nesta equivalência entre a vida e a semiose, o ego (self) é tomado por Kohn como exclusivamente pertencente ao que é vivo (analogamente ao símbolo, o ego é marca de distintividade - p. 77). Em outras palavras, "there is something unique to life: life thinks; stones don't" (p. 100).

O terceiro capítulo, "Soul Blindness", procura mostrar como a atenção para as formas de semiose dos outros seres é constitutiva da vida de qualquer ser. Este tipo de relacionalidade faz com que o ego (self) se estenda para além das fronteiras do corpo, o que, segundo Kohn, é aquilo que normalmente se entende por "alma” em Ávila (p. 106). Ter uma alma significa também ser consciente de que outros seres têm alma: ela é assim uma espécie de reificação da capacidade relacional de cada ser, o que para Kohn já era uma ideia peirceana (p. 107). A incapacidade de perceber e de se relacionar com os outros egos (selves) acarreta em um tipo perigoso de vulnerabilidade, que Kohn chama de soul blindness. 
REVISTA DE ANTROPOLOGIA, SÃO PAULO, USP, $20 \mathrm{I}$, V. $58 \mathrm{~N}^{\mathrm{O}} \mathrm{I}$.

O isolamento e o solipsismo podem ser considerados estados patológicos, pois transformam o ego em um objeto das transformaçóes corporais agenciadas por outros. Neste sentido, a alma é foco de uma atenção permanente dos nativos de Ávila. Em um sistema onde tudo o que é vivo tem alma, o perigo do canibalismo é uma constante: o caçador deve objetificar ou anular o caráter de pessoa dos animais que mata para comer (p. 119). Como é comum na Amazônia, entre os Runa as relações de predação são um lócus privilegiado para a reflexão indígena sobre o "si" e o "outro". Kohn observa que, enquanto o antropólogo, através da pesquisa de campo, experimenta intensamente outras formas de vida e relativiza as dimensóes que reputa convencionais de sua própria vida (costumes, cultura, língua), os Runa empregam outras técnicas de desfamiliarização autorreflexiva: eles não exploram a diferença cultural, mas a diferença nos tipos de corpo (p. 125).

“Trans-Species Pidgin”, o quarto capítulo do livro, volta-se para a maneira como formas de comunicação trans-específicas introduzem-se na vida humana, acompanhando etnograficamente uma série de estratégias utilizadas pelos Runa para a comunicação com seres não-humanos. A distintividade humana, até então atribuída aos modos especificamente simbólicos de semiose, inclui agora aspectos morais, presentes nas relaçôes que são produto também da história colonial (p. 133). Os "pidgins trans-específicos" são pensados como formas oblíquas ou metafóricas de comunicação: eles estabelecem uma ligação semiótica entre humanos e animais, evitando ao mesmo tempo fazer equivaler as duas perspectivas (o que arriscaria "desumanizar" o humano - p. 144). Para Kohn, eles demonstram como os Runa são conscientes dos constrangimentos formais aos quais as semióticas não-simbólicas estão submetidas (p. 148). Novamente, a comunicação inter-específica se apoia sobre uma estrutura hierárquica de perspectivas, paralela à hierarquia dos modos semióticos. 
REVISTA DE ANTROPOLOGIA, SÃO PAULO, USP, $20 \mathrm{I} 5$, V. 58 No I.

O penúltimo capítulo, "Form's Effortless Efficacy", versa sobre as dinâmicas emergentes daquilo que Kohn denomina "forma", propriedade atribuída também a sistemas não-vivos. Busca-se assim lançar luz sobre as propriedades da geração e propagação de padróes, na medida em que eles colocam em cena outro tipo de causalidade, náo restrito à imagem simples e temporalmente linear de uma cadeia de causa e efeito. Kohn procura conceituar estes "padróes de forma objetivamente reais" afastando-se simultaneamente de qualquer tipo de platonismo e de nominalismo. Segundo o autor, padróes e formas emergem mesmo de complexos inorgânicos, propagam-se sem esforço, e encetam um tipo de causalidade que congela ou ameniza os efeitos do tempo histórico (pp. 186-187). Eles compóem um tipo de generalidade naturalizada, exemplificada pelos padrôes de distribuição dos rios na Amazônia, ou pelos redemoinhos circulares que se formam nas correntezas desses rios (p. 159).

Usando o "boom" da borracha como exemplo, Kohn procura mostrar que o grande sistema exploratório montado sobre a havea, com suas estruturas de crédito e endividamento, dependia da existência destes tipos de formas emergentes na floresta (fluxos de água, dispersão das árvores de havea, a inexistência do fungo causador do "mal das folhas", etc. - pp. 160 e ss.). Este sistema mantinha com as formas emergentes uma relação análoga àquela que a semiótica simbólica mantém com os níveis semióticos mais básicos. Além disso, como todo sistema, ele dependia de duas propriedades: a "auto-similaridade através de escalas" e o "encaixamento dos padróes". Kohn propóe assim uma análise baseada nas relaçóes entre sucessivos níveis de complexidade, sendo que em cada nível surgem padróes ou formas que são a base de fenômenos mais complexos e com propriedades próprias (p. 167).

Este sistema em escalada de padróes encaixados hierarquicamente confere poder: Kohn interpreta dessa maneira o famoso caso do xamá Crispin do alto Juruá, relatado em um artigo de Manuela Carneiro da 
REVISTA DE ANTROPOlOGIA, SÃo PAULO, USP, $20 \mathrm{I} 5$, V. $58 \mathrm{~N}^{\circ} \mathrm{I}$.

Cunha (1998). Vemos que a hierarquia é considerada por Kohn uma característica imanente dos sistemas semióticos encaixados. Por isto, segundo ele, os homens são capazes de compreender as vocalizaçôes dos cachorros, que não os compreendem. Da mesma maneira, espíritos compreendem os homens, que só os compreendem com o uso xamânico de alucinógenos. Aqueles seres que ocupam uma posição mais elevada nos padróes encaixados precisam dispensar menos esforço interpretativo, já que para aquela posição "naturalmente" fluem as matérias dos sistemas contidos. Este sistema é pensado como naturalmente irreversível e não-recursivo, salvo em alguns pontos específicos, nos quais o uso de alucinógenos e o xamanismo podem fazer elementos de nível inferior apreender temporariamente a perspectiva dos níveis emergentes.

O último capítulo do livro, "The Living Future (and the Imponderable Weight of the Dead)", apresenta uma visão geral de como se encaixam no tempo as relações entre os Runa e os seus mortos, os espíritos mestres nas florestas, e os brancos. Se assumir a perspectiva de primeira pessoa supóe a capacidade de agir em uma ecologia de egos, esta agência depende da capacidade de antecipação ou de projeçáo ativa de um futuro. Antecipar o futuro, determinando-o, é fundamental para o sucesso de qualquer forma de vida, e faz com que cada ser vivo seja objeto das interpretaçóes e determinaçôes de futuro empreendidas por outros seres (p. 206). O capítulo relaciona este voltar-se para o futuro com a história de colonização e da dominação no Alto Amazonas. Para Kohn, a dominaçáo colonial envolve formas de poder que não são simplesmente impostas de fora, mas são imanentes à conformação dos sujeitos que vivem na floresta (p. 193). O capítulo pergunta entáo o que significa ser formado ou estar em formação por um poder de agir que, como foco da emergência de formas, está desde sempre implicado em relaçóes "para além do humano" (p. 193). 
REVISTA DE ANTROPOLOGIA, SÃO PAULO, USP, $20 \mathrm{I}$, V. 58 N $\mathrm{N}^{\mathrm{O}} \mathrm{I}$.

Kohn se detém ainda sobre o estatuto da morte nesta ecologia de egos das florestas. Sob a perspectiva de primeira pessoa, o ego (self) possui uma invisibilidade relativa (p. 211), ligada também ao caráter sui generis da morte como evento. O "peso imponderável dos mortos" se faz sentir no horizonte determinado pelo reino dos espíritos mestres, que, para os Runa, abriga os espectros do passado, mas ao mesmo tempo sustém o futuro, conferindo "interpretabilidade" ao mundo humano enquanto tal (p. 213). Ele emerge das tentativas humanas de engajamento semiótico na floresta e na história, e é povoado por seres que não são determinados como o "isto" objetificado da natureza ou da caça, e tampouco como o "nós" doméstico ou familiar: tratam-se de seres que ocupam a segunda pessoa, o reino da sobrenatureza.

A questão posta aos Runa é então como conviver com níveis de ordem mais elevada no sistema de encaixamento hierárquico, que ameaçam convertê-los em um "isto". Como habitar momentaneamente a perspectiva dos espíritos mestres, ou dos dominadores brancos, de maneira a converter seu poder em favor daqueles que vivem entre seus parentes? Este seria o propósito das transformaçôes operadas pelos xamâs, através da adoção de trajes e afetos que permitem aos seres habitarem o seu mundo - o uso de enfeites de dentes de onça, das roupas de branco, de pinturas corporais, etc. (p. 215). Segundo Kohn, mais que a função do xamanismo, isto é a sua condição de possibilidade: "the historical condition of possibility for shamanism is the very hierarchy it attempts to tap. Without the colonially inflected predatory hierarchy that structures the ecology of selves, there is no higher position one can enter from which to frame one's own" (p. 214).

Para Kohn, a atenção a esta ecologia semiótica pode ajudar a antropologia a "redescobrir o encantamento do mundo": "The world is animate, whether or not we are animists" (p. 217). Este reencantamento dependeria da compreensão das formas de semiose "além do humano", 
REVISTA DE ANTROPOLOGIA, SÃO PAULO, USP, $20 \mathrm{I}$, V. $58 \mathrm{~N}^{\mathrm{O}} \mathrm{I}$.

especialmente da lógica icônica que une em cadeias de similaridade tudo aquilo que a floresta pensa. Daí a importância atribuída às fotos que acompanham o texto do livro: "How Forests Think aims to think like forests: in images" (p. 222).

O livro How Forests Think apresenta assim uma elaboração teórica de fôlego, baseada em dados etnográficos recolhidos e organizados com rigor e sensibilidade. De um ponto de vista meta-teórico, no entanto, acredito que ele mereça uma consideração crítica, cujas linhas gerais pretendo esboçar a seguir.

Márcio Goldman observou certa vez que "a pretensão às grandes sínteses - ou a denúncia das falsas, tanto faz - é apenas uma estratégia de proteger a antropologia de si mesma, defendendo-a da relatividade que ela mesmo revela quando é capaz de analisar a motivação humana em um nível radical” (2011: 210). Esse é, podemos pensar, um dos grandes perigos que corre o antropólogo ao se apoiar na ideia de ontologia: colocar a teoria fora do jogo relacional que deveria ser tomado o mais conscientemente possível como a sua condição de possibilidade.

Kohn acredita que a "virada ontológica" dá à antropologia a capacidade de formular teses gerais sobre o mundo, justamente porque a generalidade é uma propriedade do mundo, que se dispersa por cadeias icônicas de similaridade. Para fazer isto, alega Kohn, seria necessário "provincializar a linguagem", determinando a semiose simbólica e a moralidade como atributos específicos do humano (enquanto espécie, por assim dizer). Esta excepcionalidade do humano, em franca oposição ao caráter irredutivamente pronominal que estes atributos têm no universo ameríndio, é postulada enquanto "tese ontológica": permanecer estritamente fiel ao que os nativos dizem seria, para Kohn, limitar o poder da antropologia em dizer o que é o mundo "para além do humano": "If we limit our thinking to thinking through how other people think we will always end up circumscribing ontology by epistemology" (p. 94). 
REVISTA DE ANTROPOLOGIA, SÃO PAULO, USP, $20 \mathrm{I}$, V. 58 N $\mathrm{N}^{\mathrm{O}} \mathrm{I}$.

Neste sentido, Kohn descreve o perspectivismo como resposta funcional às propriedades da ecologia das florestas, como uma "orientação estética contingente" particular, ou como modos localizados de um esquematismo ontológico (p. 96). Tomar o perspectivismo apenas como um objeto da teoria antropológica, anulando o seu caráter meta-teórico, permitiria ao antropólogo determinar os detentores das características "humanas" em absoluto, independentemente de qualquer relação e sem a possibilidade de reversáo. $\mathrm{O}$ "encaixamento hierárquico" das perspectivas semióticas permite assim limitar a reversibilidade, garantindo ao homem o privilégio de, sozinho, ser um self moral e simbólico. Mas, ao controlar desta forma a recursividade, Kohn termina produzindo um discurso cuja forma lógica é muito semelhante àquela que ele descreve para o extrativismo gomífero: os Runa aparecem como base para as suas formulaçôes, mas são mantidos em um nível distinto daquele do antropólogo. Kohn assume uma perspectiva acima das explicaçôes Runa, extraindo delas o poder de determinar "ontologicamente" a realidade "para além do humano".

How Forests Think parece assim optar pelo abando de uma das contribuiçóes fundamentais dadas para a teoria antropológica por, por exemplo, Roy Wagner (2010) ou Viveiros de Castro (2009): a ideia de que a teoria antropológica deve estar sempre no mesmo nível que o seu "objeto", ou de que toda teoria é uma contrateoria e toda ontologia uma contra-ontologia. Dito de outro modo, a "ontologia" de que se fala em antropologia deveria ser tomada sempre e o mais explicitamente possível como o resultado do encontro etnográfico: invenção da ontologia, como quem diz invenção da cultura. 
REVISTA DE ANTROPOLOGIA, SÃO PAULO, USP, $20 \mathrm{I} 5, \mathrm{~V} .58 \mathrm{~N}^{\mathrm{O}} \mathrm{I}$.

\section{Referências bibliográficas}

Carneiro da Cunha, Manuela

1998 "Pontos de vista sobre a floresta amazônica: xamanismo e tradução". Mana, vol. 4, n. 1: 7-22.

Goldman, Márcio

2011 "O fim da antropologia”. Revista Novos Estudos - Cebrap, Sáo Paulo, n. 89: 195-211.

KoHn, Eduardo

2013 How forests think. Berkeley, University of California Press.

Viveiros de Castro, Eduardo

2009 Métaphysiques cannibales. Paris, PUF.

WAGNER, Roy

2010 A invenção da cultura. Trad. Marcela Coelho de Souza e Alexandre Morales. São Paulo, Cosac Naify. 